\title{
Ankle joint pressure change in varus malalignment of the tibia
}

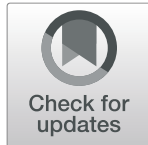

Yuan $\mathrm{Zhu}^{1+}$, Xingchen $\mathrm{Li}^{2+}$ and Xiangyang $\mathrm{Xu}^{{ }^{*}}$

\begin{abstract}
Background: Varus malalignment of the tibia could alter ankle biomechanics, and might lead to degenerative changes of the ankle joint. However, previous studies failed to report the detailed changes of ankle biomechanics in varus malalignment of the tibia. The aim of this biomechanical study was to evaluate how the ankle joint pressure would change in response to the incremental increases in varus malalignment of the tibia.

Methods: Eight fresh-frozen human cadaver legs were tested in this study. Varus malalignment of the tibia and a total of $600 \mathrm{~N}$ compressive force was simulated using a custom made fixture. Intra-articular sensors (TeckScan) were inserted in the ankle joint to collect the ankle joint pressure data. The testing sequence was $0^{\circ}, 2^{\circ}, 4^{\circ}, 6^{\circ}, 8^{\circ}, 10^{\circ}, 12^{\circ}, 14^{\circ}$, $16^{\circ}, 18^{\circ}, 20^{\circ}$ of tibial varus.

Results: As the tibial varus progressed, the center of force (COF) shifted laterally both for the medial and lateral aspect of the ankle joint. For the medial aspect of the ankle joint, the lateral shift reached its maximum at $8^{\circ}[2.76$ (1.62) $\mathrm{mm}, p=0.002$ ] of tibial varus, while for the lateral aspect of the ankle joint, the lateral shift reached its maximum at $12^{\circ}[2.11(1.19) \mathrm{mm}, p=0.002]$ of tibial varus. Thereafter, the COF shifted medially as the tibial varus progressed. For the lateral aspect of the ankle joint, The $P_{\text {mean }}$ increased from 2103.8 (625.1) $\mathrm{kPa}$ at $0^{\circ}$ to 2295.3 (589.7) $\mathrm{kPa}$ at $8^{\circ}$ of tibial varus $(p=0.047)$, significant difference was found between the $\mathrm{P}_{\text {mean }}$ at $0^{\circ}$ and $8^{\circ}(p=$ $0.047)$ of tibial varus. Then as the tibial varus progressed, the $P_{\text {mean }}$ decreased to 1748.9 (467.2) $\mathrm{kPa}$ at $20^{\circ}$ of tibial varus $(p=0.002)$. The lateral joint pressure ratio also increased from $0.481(0.125)$ at $0^{\circ}$ to $0.548(0.108)$ at $10^{\circ}$ of tibial varus $(p=0.002)$, then decreased to $0.517(0.101)$ at $20^{\circ}$ of tibial varus $(p=0.002)$.
\end{abstract}

Conclusions: For mild tibial varus deformities, there was a lateral shift of COF and lateral stress concentration within the ankle joint. However, as the tibial varus progressed, the COF shifted medially and the lateral stress concentration decreased.

Keywords: Ankle biomechanics, Tibial varus, Joint pressure measurement

\section{Background}

The alignment of the lower extremity is critical for orthopaedic surgeons, both for preoperative and postoperative evaluation. It is believed that the varus or valgus deformity of the lower extremity is highly associated with osteoarthritis, especially the knee joint [1-4]. Previous study

\footnotetext{
*Correspondence: xu664531@126.com

†Yuan Zhu and Xingchen Li contributed equally to this work

${ }^{1}$ Department of Orthopaedics, Ruijin Hospital, Shanghai Jiaotong, University School of Medicine, Shanghai, China

Full list of author information is available at the end of the article
}

demonstrated that the knee joint alignment and kinematics was altered in patients with early knee ostoearthritis [5]. Patient with varus knee often had a varus inclined tibia, which could subsequently alter normal biomechanics of the ankle joint. It was thought that varus tibia can lead to stress concentration on the medial aspect of the ankle joint, prolonged stress will result in degenerative changes of the cartilage within the ankle joint [6].

Norton and colleagues [7] studied the compensatory mechanism of hindfoot for advanced knee osteoarthritis, they found that as the mechanical axis angle became

(c) The Author(s). 2020 Open Access This article is licensed under a Creative Commons Attribution 4.0 International License, which permits use, sharing, adaptation, distribution and reproduction in any medium or format, as long as you give appropriate credit to the original author(s) and the source, provide a link to the Creative Commons licence, and indicate if changes were made. The images or other third party material in this article are included in the article's Creative Commons licence, unless indicated otherwise in a credit line to the material. If material is not included in the article's Creative Commons licence and your intended use is not permitted by statutory regulation or exceeds the permitted use, you will need to obtain permission directly from the copyright holder. To view a copy of this licence, visit http://creativecommons.org/licenses/by/4.0/. The Creative Commons Public Domain Dedication waiver (http://creativecommons.org/publicdomain/zero/1.0/) applies to the data made available in this article, unless otherwise stated in a credit line to the data. 
either more varus or valgus, the hindfoot would subsequently orient in more valgus or varus position in order to maintain a normal mechanical alignment of the lower extremity. Therefore, for patients with varus malalignment of the tibia, would the compensatory mechanism further affect the ankle joint biomechanics? Ting and colleagues [8] found that anterior and posterior bow deformities produced a greater change in contact area of the tibiotalar joint than with valgus or varus deformities. The subtalar joint might have compensated for varua and valgus deformities. The PreScale TM pressuresensitive film was utilized for the measurement of contact area and pressure, and $0^{\circ}, 5^{\circ}, 10^{\circ}, 15^{\circ}$ of deformities was simulated. They failed to report the detailed ankle joint pressure change in response to the incremental increases in varus malalignment of the tibia.

The aim of this biomechanical study was to investigate the detailed ankle joint pressure change as the tibial varus progressed. We hypothesized that the pressure on the lateral aspect of the ankle joint will increase as the result of valgus inclination of the subtalar joint in response to the varus tibia malalignment. As the varus deformity progressed, the valgus inclination of the subtalar joint would reach its' maximum and then fail, thereafter, the subtalar joint would convert into a varus inclination resulting a sudden medial stress concentration.

\section{Methods}

A total of 8 fresh-frozen human cadaver legs were utilized for the biomechanical testing, the specimens were thawed to room temperature $\left(24^{\circ} \mathrm{C}\right)$. The mean age of the cadavers was 71.4 (7.4) years old, 4 of the 8 were men and 4 of the 8 were right foot. X-rays were obtained for each specimen and none of them had malalignment of the tibia, hindfoot, nor preexisting subtalar joint osteoarthritis. All specimens had normal range of motion of both ankle and subtalar joint. The anterior soft tissue (including skin, subcutaneous tissue, anterior joint capsule, tendons and neurovascular bundles) of the ankle joint were dissected for the access to the ankle joint. Both the medial and lateral ankle ligaments were well preserved.

The tibia and fibula was cut at $20 \mathrm{~cm}$ above the ankle joint. For each specimen, the proximal tibia and fibula was potted securely into a custom made shell, then mounted on a custom made fixture. The tibia and fibula was embedded and securely fixed into the shell using dental gypsum. Load was applied to the tibia and fibula via the custom made shell. Each specimen must be potted in neutral position, no plantarflexion or dorsiflexion of the ankle joint in sagittal plane, no varus or valgus malalignment of the hindfoot in coronal plane, no internal or external rotation of the foot in horizontal plane.
The custom designed fixture was utilized for the testing. Spirit levels were utilized to make sure both the working table and the top plate was horizontal throughout the entire testing process. The varus malalignment of tibia $\left(0^{\circ}, 2^{\circ}, 4^{\circ}, 6^{\circ}, 8^{\circ}, 10^{\circ}, 12^{\circ}, 14^{\circ}, 16^{\circ}, 18^{\circ}, 20^{\circ}\right.$ of tibial varus $)$ was simulated by a custom made apparatus. Each hole on the apparatus represented a specific varus angle. A bolt was used to fix the specimen at a desired varus angle (Fig. 1).

The four threaded polyethylene pillars were utilized to connect the top plate, the compressive forces were exerted via the four pillars. Sensor cells were placed in each pillar, a monitor was connected to each sensor cell, displaying the real-time force. Springs were placed right above each force sensor, then followed by nuts, compressive forces could be generated by twisting the nut on the spring.

The sensor pads (Model 6900, TekScan, Inc., South Boston, MA), with each pad measuring $14 * 14 \mathrm{~mm}$, each pad had 121 senels (11*11 sensels), the column and row spacing was $1.3 \mathrm{~mm}$, resulting in a spatial resolution of $0.62 \mathrm{~mm}^{2}$ per sensel. Two pads were put side by side within the ankle joint for the measurement of the ankle joint pressure. The sensor pads were inserted into the

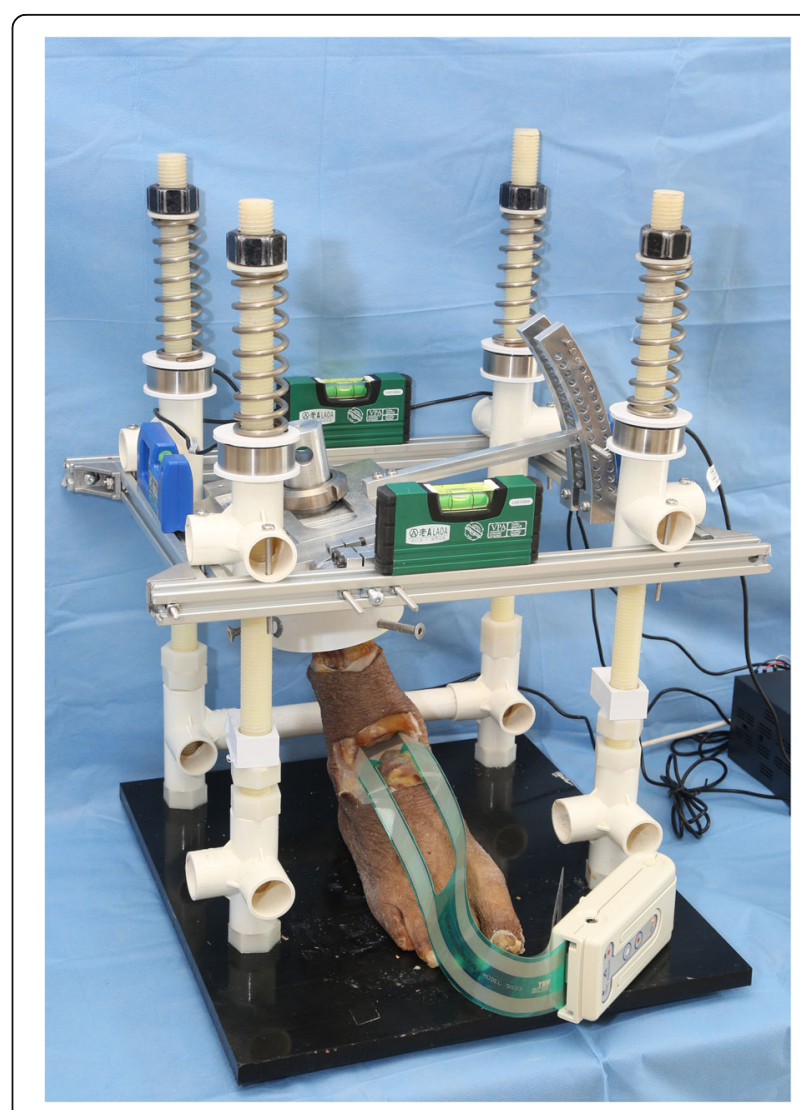

Fig. 1 The custom made fixture, the varus malalignment of the tibia was simulated by inserting the bolt into specific holes 
ankle joint from anterior and secured by thumbtacks to the distal tibial metaphysis and the foot in order to avoid sensor motion during testing $[9,10]$. The sensor pads were connected to the handle which could be further connected to a personal computer, data including pressure, force was collected using I-Scan software (Fig. 2).

The baseline ankle joint pressure distribution was initially collected for each specimen. The specimen was fixed at $0^{\circ}$ of tibial varus by inserting a bolt, the foot was then placed onto the floor freely. A compressive force was generated through the 4 pillars by twisting the nuts. Making sure the top plate was maintained horizontally throughout the testing. A $600 \mathrm{~N}$ compressive force was applied to simulate the normal load within the ankle joint during ambulation. Both the medial and lateral ankle joint pressure data was collected. Then free the specimen by removing the bolt and then the top plate of the fixture was lifted upward, followed by $2^{\circ}$ of tibial varus, then $4^{\circ}, 6^{\circ}, 8^{\circ}, 10^{\circ}, 12^{\circ}, 14^{\circ}, 16^{\circ}, 18^{\circ}, 20^{\circ}$. Both the medial and lateral aspect of the ankle joint pressure data were collected for each alignment.

\section{Statistical analysis}

SPSS V.23 software (IBM Inc., New York) was used for the data analysis. Matlab was used for the calculation of the center of force $(\mathrm{COF})$ shift, the peak pressure $\left(\mathrm{P}_{\max }\right)$ and the mean pressure $\left(\mathrm{P}_{\text {mean }}\right)$. The lateral shift of COF relative to the ankle joint was defined as positive, the medial shift was defined as negative. S-W test was used for the test of normality. Paired student $t$ test was utilized to determine the significant differences for the COF shift, $P_{\max }$ and $\mathrm{P}_{\text {mean }}$ at different working conditions. The level of significance was set to a $p$ value $<0.05$.

\section{Results}

The COF shift

As the tibial varus progressed from $0^{\circ}$ to $20^{\circ}$ of tibial varus, the COF shifted laterally both for the medial and lateral aspect of the ankle joint initially, then the $\mathrm{COF}$ converted to shift medially as the tibial varus progressed to $20^{\circ}$. The maximum lateral shift of the medial COF was noticed at $8^{\circ}$ [2.76 (1.62) $\left.\mathrm{mm}, p=0.002\right]$ of tibial varus. Then the COF shifted medially as the tibial varus progressed, the lateral shift of the medial aspect $\mathrm{COF}$ was $-1.46(1.08) \mathrm{mm}$ at $20^{\circ}$ of tibial varus, significant difference was found between $8^{\circ}$ and $20^{\circ}$ of tibial varus, $p=0.001$ (Fig. 3). While the maximum lateral shift of the lateral COF was noticed at $12^{\circ}[2.11$ (1.19) $\mathrm{mm}, p=$ 0.002] of tibial varus, then it converted to shift medially as the tibial varus progressed from $12^{\circ}$ to $20^{\circ}$. The lateral shift for the lateral aspect of COF was $0.65(0.69) \mathrm{mm}$ at $20^{\circ}$ of tibial varus, significant difference was found between $12^{\circ}$ and $20^{\circ}$ of tibial varus, $p=0.026$ (Fig. 4) (Table 1).

\section{The $P_{\max }$}

As the tibial varus progressed from $0^{\circ}$ to $20^{\circ}$ of tibial varus, it seemed that the $\mathrm{P}_{\max }$ for both the medial and lateral aspect of the ankle joint decreased gradually. It was $5303.4(1105.1) \mathrm{kPa}$ at $0^{\circ}$ and $4432.1(948.6) \mathrm{kPa}$ at $20^{\circ}$ of tibial varus for the medial aspect of the ankle joint, significant difference was found for the medial $\mathrm{P}_{\max }$ at $0^{\circ}$ and $2^{\circ}(p=0.032), 0^{\circ}$ and $18^{\circ}(p=0.039), 0^{\circ}$ and $20^{\circ} \quad(p=0.045)$ of tibial varus. However, it was $5135.5(1095.3) \mathrm{kPa}$ at $0^{\circ}$ and $4279.4(666.9) \mathrm{kPa}$ at $20^{\circ}$ of tibial varus for the lateral aspect of the ankle joint, significant difference was only found for the lateral $\mathrm{P}_{\max }$ at $0^{\circ}$ and $2^{\circ}$ of tibial varus, $p=0.022$. (Table 1 ).

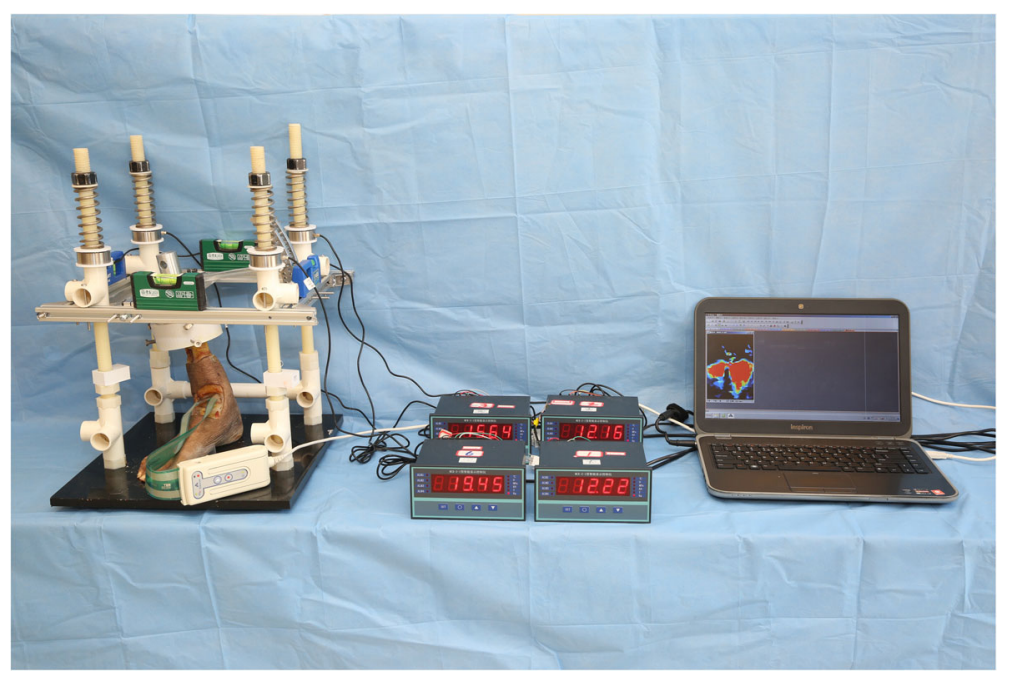

Fig. 2 The specimen was mounted in the custom made fixture, the force applied on each pillar could be read on the screen and the real-time joint pressures were collected 


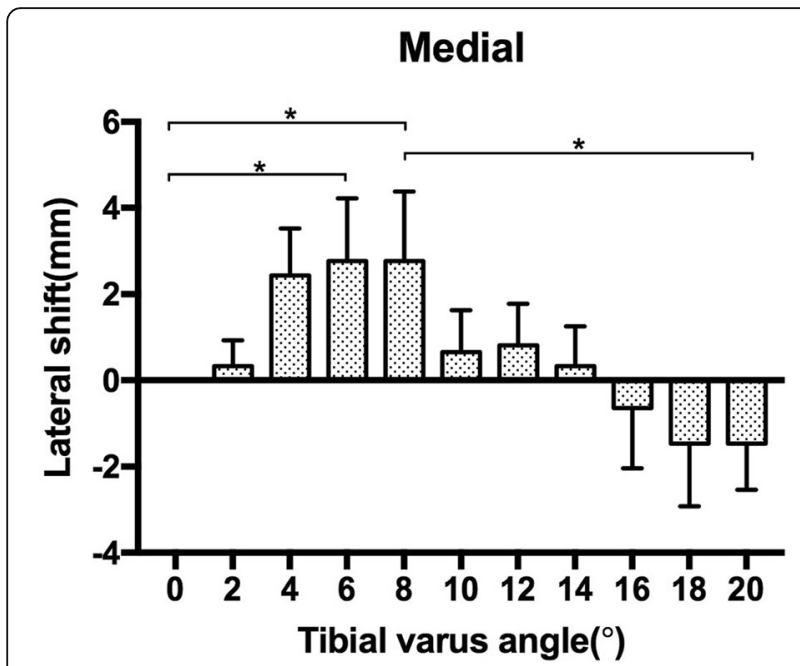

Fig. 3 The lateral shift of medial COF as the tibial varus deformity progressed. The asterisk $(*)$ denotes significant difference

The $\mathrm{P}_{\text {mean }}$

The $\mathrm{P}_{\text {mean }}$ for the medial aspect of the ankle joint was $2266.4(672.7) \mathrm{kPa}$ at $0^{\circ}, 1891.2(563.9) \mathrm{kPa}$ at $10^{\circ}$ and $1618.7(421.5) \mathrm{kPa}$ at $20^{\circ}$ of tibial varus. When compared with the baseline mean pressure at $0^{\circ}$, significant differences were found for both $10^{\circ}(p=0.007)$ and $20^{\circ}(0.006)$ of tibial varus. The $\mathrm{P}_{\text {mean }}$ for the medial aspect of the ankle joint decreased as the tibial varus progressed from $0^{\circ}$ to $20^{\circ}$ of tibial varus (Fig. 5). However, for the lateral aspect of the ankle joint, the $\mathrm{P}_{\text {mean }}$ increased gradually from $0^{\circ}$ to $8^{\circ}$ of tibial varus, it was $2103.8(625.1) \mathrm{kPa}$ at $0^{\circ}$ and $2295.3(589.7) \mathrm{kPa}$ at $8^{\circ}$ of tibial varus, significant difference was found between the $\mathrm{P}_{\text {mean }}$ at $0^{\circ}$ and $8^{\circ}(p=$

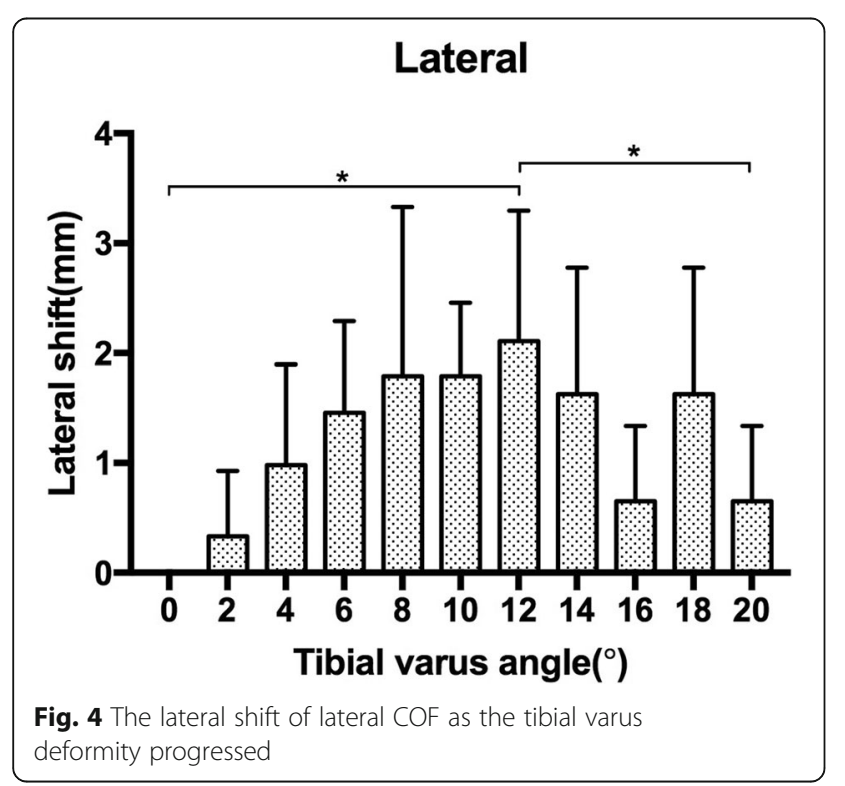

$0.047)$ of tibial varus. Then as the tibial varus progressed from $8^{\circ}$ to $20^{\circ}$, it converted to decrease and plummeted to $1748.9(467.2) \mathrm{kPa}$ at $20^{\circ}$ of tibial varus, significant difference was found between the $\mathrm{P}_{\text {mean }}$ at $8^{\circ}$ and $20^{\circ}$ $(p=0.002)$ of tibial varus (Fig. 6) (Table 1$)$.

\section{The lateral joint pressure ratio}

In order to investigate the joint pressure change on the medial and lateral aspect of the ankle joint, we introduced the lateral joint pressure ratio, it was a ratio of the lateral mean pressure divided by the whole joint mean pressure. It seemed that the lateral joint pressure ratio increased from $0^{\circ}$ to $10^{\circ}$ of tibial varus, it was 0.481 $(0.125)$ at $0^{\circ}$ and $0.548(0.108)$ at $10^{\circ}$ of tibial varus, significant difference was found between these two conditions $(p=0.002)$. As the tibial varus continued to progress from $10^{\circ}$ to $20^{\circ}$, it seemed that the lateral joint pressure ratio decreased. It was $0.517(0.101)$ at $20^{\circ}$ of tibial varus, significant difference was found between these two conditions $(p=0.002)$ (Fig. 7) (Table 1).

\section{Discussion}

It had been widely recognized that varus ankle deformity was associated with varus type ankle osteoarthritis [1113]. We assumed that the prolonged exposure to eccentric loading on the medial aspect of the ankle joint will result in stress concentration and the continuous eccentric loading may develop degenerative changes of the cartilage and lead to osteoarthritis eventually.

However, according to our biomechanical study, we failed to find any evidence for medial stress concentration as the tibial varus progressed to $20^{\circ}$. The $\mathrm{P}_{\max }$ on both the medial and lateral aspect of the ankle joint decreased as the tibial varus progressed from $0^{\circ}$ to $20^{\circ}$. And so did the $\mathrm{P}_{\text {mean }}$ for the medial aspect of the ankle joint, from 2266.4 (672.7) $\mathrm{kPa}$ at $0^{\circ}$ to $1618.7(421.5) \mathrm{kPa}$ at $20^{\circ}$ of tibial varus. Oneda and colleagues [14] reported a similar result, they performed a biomechanical investigation using a rigid-body spring model and concluded that varus deformity of the distal joint surface of tibia by itself does not result in medial stress concentration in the ankle. Why the opposite was observed?

Hayashi and colleagues [15] retrospectively reviewed 133 ankles in 80 patients (OA group) and 62 ankles in 50 subjects (control group). The weightbearing X-rays were investigated, and they concluded that the valgus inclination of the subtalar joint progressed until the intermediate stage and converted to varus position at the later stage. Wang and colleagues [16] retrospectively investigated the X-rays of 233 ankles in 226 patients and 60 ankles from 60 subjects. They concluded that the subtalar joint often compensated for the malaligned ankle in static weightbearing, however, the compensatory mechanism often relied on the health condition of 


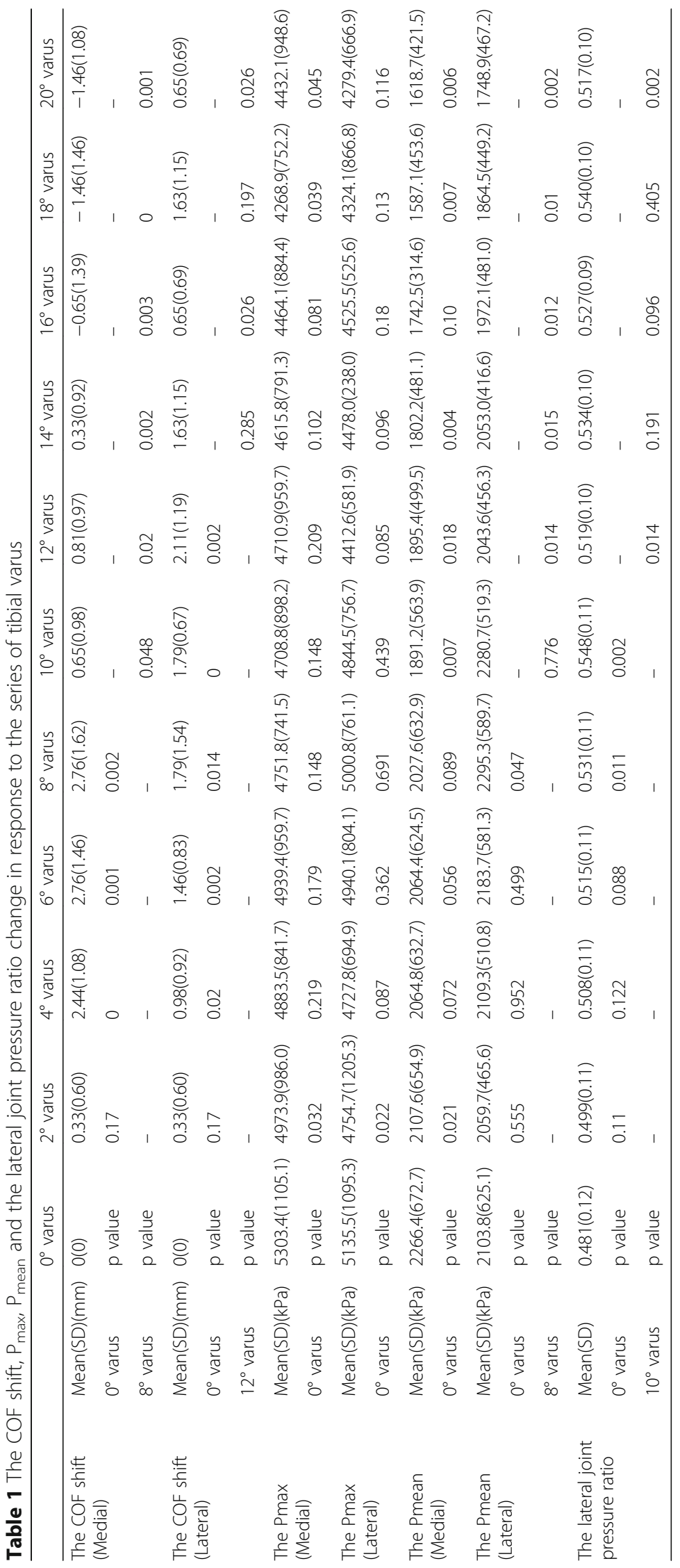




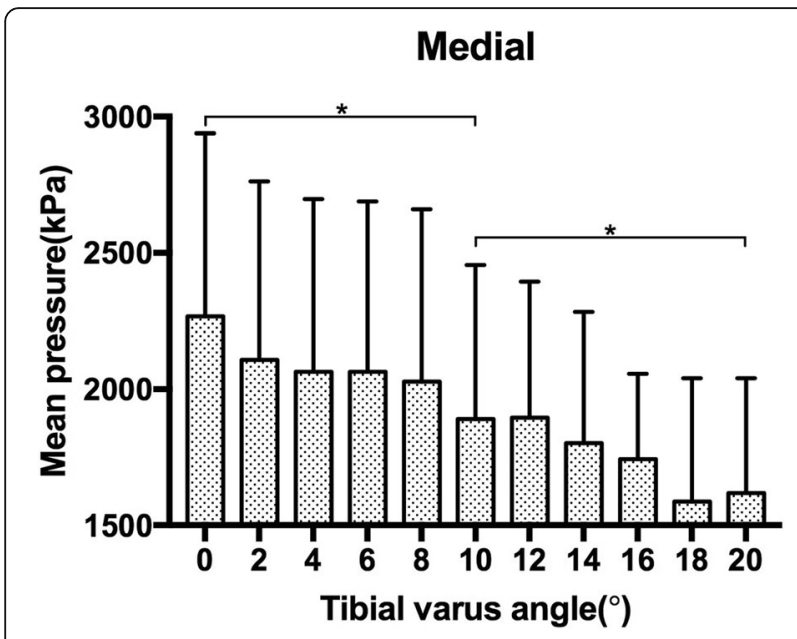

Fig. 5 The mean pressure of the medial aspect of the ankle joint as tibial varus progressed

the subtalar joint, the healthier the subtalar joint, the more it could compensate for the malaligned ankle joint. Krahenbuhl and colleague [17] retrospectively investigated subtalar joint alignment of 88 patients and 27 healthy volunteers in different stages of ankle OA using weightbearing CT scans. A more valgus subtalar joint alignment was found in patients with varus ankle OA, compensation did not correlate with the stage of ankle OA.

These studies also demonstrated that the subtalar joint does compensate for the varus ankle deformity. However, they failed to explain how this compensatory mechanism happened and whether this compensation would alter the joint pressure distribution within the ankle joint. In this biomechanical test, we found a lateral shift of COF and lateral stress concentration for mild

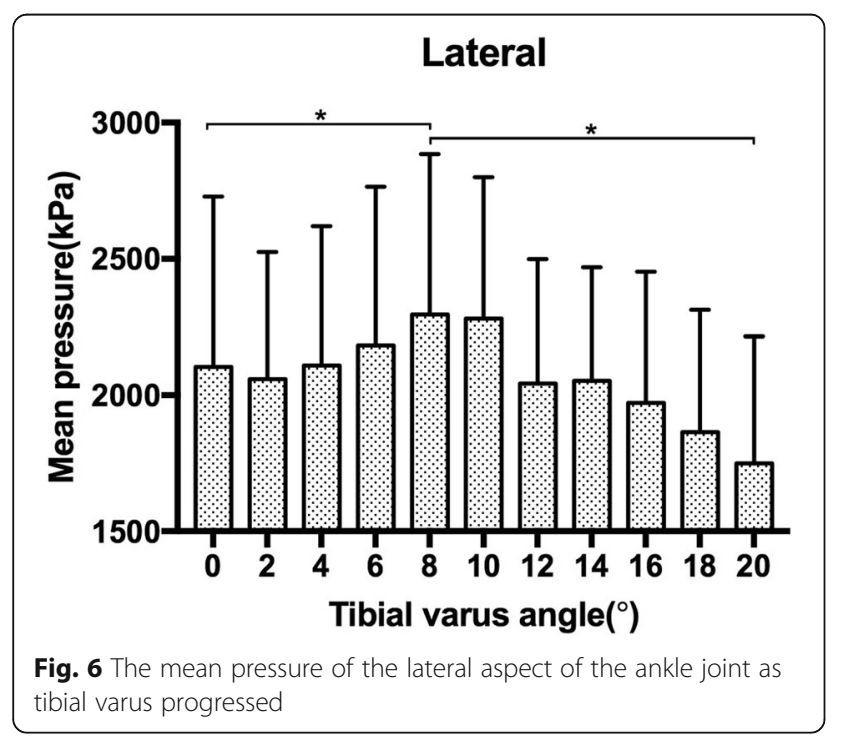

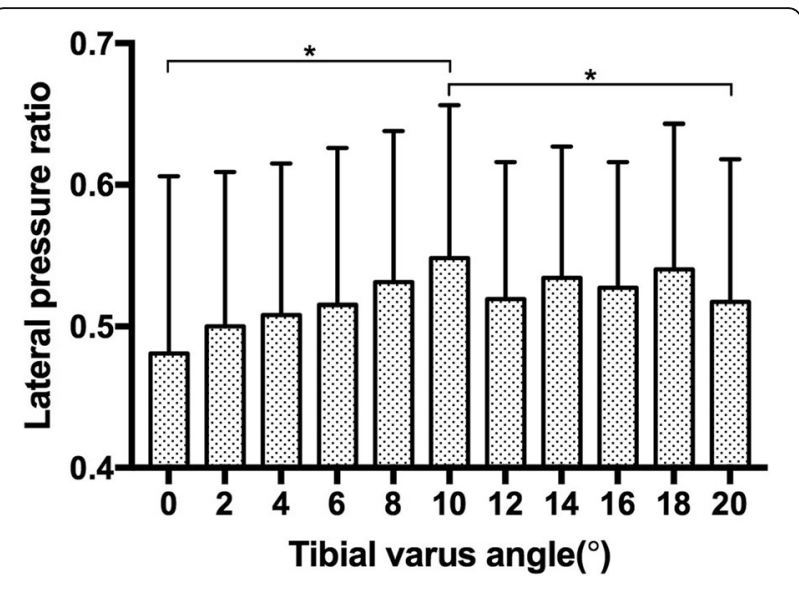

Fig. 7 The lateral joint pressure ratio as the tibial varus progressed

varus deformities. As the tibial varus progressed from $0^{\circ}$ to $20^{\circ}$, the COF for both medial and lateral aspect of the ankle joint shifted laterally till around $10^{\circ}$ of tibial varus, and then shifted medially as the tibial varus progressed. The mean pressure of the lateral aspect of the ankle joint increased till about $10^{\circ}$ of tibial varus, and then converted to decrease as the tibial varus continued to progress. This phenomenon could be explained by the compensation of the subtalar joint. The subtalar joint played a significant role in maintaining the talus in its normal relationship to the tibia, it acted as a torque transmitter and compensates for tibial varus deformities $[7,8,18]$. As calcaneus was in contact with the ground, the subtalar joint would compensate for the varus tilted ankle joint in order to maintain a normal hindfoot alignment. This valgus inclination of calcaneus might result in stress concentration on the lateral aspect of ankle joint and lateral shift of the COF as well. In addition, subtalar joint restriction could result in a decrease in lateral tibiotalar contact caused by the inhibition of calcaneal eversion [8]. So our biomechanical study favored these studies, the subtalar joint might have compensated for deformity above the ankle joint. According to Hayashi and colleagues [15], they found that the valgus inclination of subtalar joint will convert into varus inclination as the varus ankle deformity increase, because of the failure of subtalar joint compensation. However, in this study, we failed to find a sudden medial stress concentration even with a $20^{\circ}$ of tibial varus. Further studies should be needed to explore whether the medial stress concentration would occur as the deformity reached greater than $20^{\circ}$ of tibial varus.

There are some limitations for this study. First of all, this is a preliminary study which only included the joint pressure data, the compensatory mechanism of the subtalar joint should be supported by adding the radiological data of both the ankle and subtalar joint 
(including CT data and weightbearing X-rays). Further studies are needed to fully understand the compensatory mechanism of the subtalar joint. Second limitation is that this is a static biomechanical study, the ankle and subtalar joint biomechanics might act differently in vivo, we also neglected the tendon forces around the ankle joint in this study.

\section{Conclusions}

We found a lateral shift of the COF and lateral stress concentration for mild tibial varus. However, as the tibial varus continued to progress, the COF shifted medially and the lateral stress concentration decreased. This phenomenon might be explained by the valgus inclination of subtalar joint in compensation for the varus tibial malalignment. However, further biomechanical studies are needed to fully understand the compensatory mechanism of the subtalar joint.

\section{Abbreviations}

COF: Center of force; OA: Osteoarthritis

\section{Acknowledgements}

None.

\section{Authors' contributions}

$Y Z$ drafted the manuscript and performed the statistical analysis, $X L$ helped to draft the manuscript and carried out the data collections, XX designed the study and helped to draft the manuscript. The authors read and approved the final manuscript.

\section{Funding}

This study was supported by grants from the National Natural Science Foundation of China grants (NO. 81772372) and the Shanghai Municipal Commission of Health and Family Planning (Grant Number 201540102). The authors disclosed receipt of financial support from these two research grants for the research and publication of this article.

\section{Availability of data and materials}

All the data supporting our findings was contained within the manuscript. And all data in this study was freely available to any researcher for noncommercial purposes.

\section{Ethics approval and consent to participate}

This study was approved by the ethics committee of Ruijin Hospital, Shanghai JiaoTong University.

School of Medicine. Written consent to donate their body was obtained from the individuals and their body was indeed donated only for research or scientific purposes.

\section{Consent for publication}

Written consent to publish the related images or clinical details of specimens was provided by donors included in the study.

\section{Competing interests}

The authors have no conflict of interest.

\section{Author details}

'Department of Orthopaedics, Ruijin Hospital, Shanghai Jiaotong, University School of Medicine, Shanghai, China. ${ }^{2}$ Department of Orthopaedics, Ruijin Hospital North, Shanghai Jiaotong, University School of Medicine, Shanghai, China.
Received: 12 November 2019 Accepted: 25 February 2020

Published online: 04 March 2020

\section{References}

1. Rossi R, Bonasia DE, Amendola A. The role of high tibial osteotomy in the varus knee. J Am Acad Orthop Surg. 2011;19(10):590-9.

2. Amis AA. Biomechanics of high tibial osteotomy. Knee Surg Sports Traumatol Arthrosc. 2013;21(1):197-205.

3. McNamara I, et al. High tibial osteotomy: evolution of research and clinical applications--a Canadian experience. Knee Surg Sports Traumatol Arthrosc 2013;21(1):23-31.

4. Herman BV, Giffin JR. High tibial osteotomy in the ACL-deficient knee with medial compartment osteoarthritis. J Orthop Traumatol. 2016;17(3):277-85.

5. Baier $C$, et al. Different kinematics of knees with varus and valgus deformities. J Knee Surg. 2018;31(3):264-9.

6. Krause $F$, et al. Ankle joint pressure in pes cavovarus. J Bone Joint Surg (Br). 2007;89(12):1660-5.

7. Norton AA, et al. Correlation of knee and hindfoot deformities in advanced knee OA: compensatory hindfoot alignment and where it occurs. Clin Orthop Relat Res. 2015:473(1):166-74.

8. Ting AJ, et al. The role of subtalar motion and ankle contact pressure changes from angular deformities of the tibia. Foot Ankle. 1987;7(5):290-9.

9. Krause FG, et al. Ankle joint pressure changes in a pes cavovarus model after lateralizing calcaneal osteotomies. Foot Ankle Int. 2010;31(9):741-6.

10. Schmid T, et al. Ankle joint pressure changes in a pes cavovarus model: supramalleolar valgus osteotomy versus lateralizing calcaneal osteotomy. Foot Ankle Int. 2013;34(9):1190-7.

11. Takakura $Y$, et al. Low tibial osteotomy for osteoarthritis of the ankle. Results of a new operation in 18 patients. J Bone Joint Surg (Br). 1995;77(1):50-4.

12. Stamatis ED, Cooper PS, Myerson MS. Supramalleolar osteotomy for the treatment of distal tibial angular deformities and arthritis of the ankle joint. Foot Ankle Int. 2003;24(10):754-64.

13. Hintermann B, Knupp M, Barg A. Supramalleolar osteotomies for the treatment of ankle arthritis. J Am Acad Orthop Surg. 2016;24(7):424-32.

14. Tanaka $Y$. The concept of ankle joint preserving surgery: why does supramalleolar osteotomy work and how to decide when to do an osteotomy or joint replacement. Foot Ankle Clin. 2012;17(4):545-53.

15. Hayashi K, et al. Correlation of compensatory alignment of the subtalar joint to the progression of primary osteoarthritis of the ankle. Foot Ankle Int. 2008;29(4):400-6.

16. Wang B, et al. Does the subtalar joint compensate for ankle malalignment in end-stage ankle arthritis? Clin Orthop Relat Res. 2015:473(1):318-25.

17. Krahenbuhl N, et al. Orientation of the Subtalar joint: measurement and reliability using Weightbearing CT scans. Foot Ankle Int. 2016;37(1):109-14.

18. Mullaji A, Shetty GM. Persistent hindfoot valgus causes lateral deviation of weightbearing axis after total knee arthroplasty. Clin Orthop Relat Res. 2011; 469(4):1154-60

\section{Publisher's Note}

Springer Nature remains neutral with regard to jurisdictional claims in published maps and institutional affiliations.

Ready to submit your research? Choose BMC and benefit from:

- fast, convenient online submission

- thorough peer review by experienced researchers in your field

- rapid publication on acceptance

- support for research data, including large and complex data types

- gold Open Access which fosters wider collaboration and increased citations

- maximum visibility for your research: over $100 \mathrm{M}$ website views per year

At $\mathrm{BMC}$, research is always in progress.

Learn more biomedcentral.com/submission 